\title{
Comparison of Supraclavicular, Infraclavicular, and Axillary Approaches for Ultrasound-Guided Brachial Plexus Block for Upper Limb Surgeries: A Retrospective Analysis of 182 Blocks
}

\author{
Ebru Tarıkçı Kılıç Mehmet Salim Akdemir \\ Anesthesiology and Reanimation Department, Ümraniye Training and Research Hospital, Health Sciences \\ University, İstanbul, Turkey
}

\section{Keywords}

Axillary approach - Brachial plexus block - Infraclavicular approach · Supraclavicular approach · Ultrasound-guided block

\section{Abstract \\ Background: Supraclavicular (SCL), infraclavicular (ICL), and axillary (AX) brachial plexus nerve blocks are used for the up- per extremity. Regional nerve blocks should be considered for their beneficial effects and less risk of complications. Ob- jectives: The aim of this study was to conduct a retrospective evaluation of our experiences in ultrasound (US)-guided techniques of the SCL-ICL and $A X$ approaches for brachial plexus block (BPB) in producing high-quality surgical anes- thesia for operations below the shoulder. Methods: The re- cords of 182 American Society of Anesthesiologists (ASA) grade I-III patients undergoing upper extremity and vascu- lar surgeries under BPB by US guidance were evaluated. SCL, $A X$, and ICL approaches were used. A linear US probe was used for all patients. Data pertaining to demographic char- acteristics, ASA physical status, underlying diseases, block type, time between the block performance and the start of the operation, duration of the operation, type of surgeries,}

needle length, toxicity findings, postoperative complications, and success rates were assessed. Results: Demographic data were found to be similar with no statistically significant differences between the study groups $(p>0.05)$. The three groups were also similar in ASA physical status, type of surgery, the experience of the anesthesiologists who performed the blocks, the time between the end of the block performance and the start of the operation, and the quality of the surgical anesthesia. Transient Horner's syndrome was detected in 3 patients in the SCL group and in 1 patient in the ICL group. Conclusions: All three approaches can be used for US-guided BPB with adequate quality of surgical anesthesia.

(c) 2018 The Author(s)
Published by S. Karger AG, Basel

\section{Introduction}

Peripheral nerve blocks offer safe conditions for highrisk situations due to their cost-effectiveness. Brachial plexus block (BPB) using the classical approach is a blind technique with a higher failure rate and injury to the nerves. To allow a time-tested and better localization of the nerves and the surrounding structures, ultrasound

\begin{tabular}{ll}
\hline KARGER & $\begin{array}{l}\text { @ 2018 The Author(s) } \\
\text { Published by S. Karger AG, Basel }\end{array}$ Oparger \\
E-Mail karger@karger.com & $\begin{array}{l}\text { Thisis an Open Access article licensed under the Creative Commons } \\
\text { Attribution-NonCommercial-4.0 International License (CC BY-NC) } \\
\text { (http://www.karger.com/Services/OpenAccessLicense), applicable to } \\
\text { the online version of the article only. Usage and distribution for } \\
\text { commercial purposes requires written permission. }\end{array}$
\end{tabular}


Table 1. Demographic variables

\begin{tabular}{lcccc}
\hline & SCL $(n=62)$ & ICL $(n=55)$ & AX $(n=65)$ & $p$ value \\
\hline Age, years & $55 \pm 13.4$ & $58 \pm 15.77$ & $57 \pm 20.55$ & 0.43 \\
Weight, kg & $72.55 \pm 20.01$ & $74.64 \pm 13.43$ & $80.34 \pm 20.58$ & 0.25 \\
Gender (M:F) & $35: 25$ & $28: 32$ & $31: 29$ & 0.30 \\
ASA physical status (I/II/III) & $25 / 15 / 22$ & $18 / 26 / 11$ & $15 / 30 / 20$ & \\
Time between end of block & & & & 0.33 \\
$\quad$ and start of operation, min & $88.53 \pm 50.08$ & $73.43 \pm 60.23$ & $67.45 \pm 34.90$ & 0.28 \\
Duration of operation, min & $80.50 \pm 33.43$ & $65.04 \pm 23.09$ & $79.75 \pm 35.78$ & 0.82 \\
Duration of block, min & $22.40 \pm 5.23$ & $20.47 \pm 7.33$ & $20.47 \pm 7.33$ & \\
\hline
\end{tabular}

ASA, American Society of Anesthesiologists; AX, axillary; ICL, infraclavicular; SCL, supraclavicular.

Table 2. Type of orthopedic surgeries with success rates

\begin{tabular}{lll}
\hline SCL & $\begin{array}{l}\text { Carpal tunnel release } \\
\text { Wrist fusion } \\
\text { Tendon release and suturing of the tendon } \\
\text { Carpometacarpal arthrodesis }\end{array}$ & $94 \%$ \\
\hline $\mathrm{AX}$ & $\begin{array}{l}\text { Olecranon bursectomy } \\
\text { Ganglion excision of the hand }\end{array}$ & $91.6 \%$ \\
& Ulnar nerve compression & \\
\hline ICL & $\begin{array}{l}\text { Fracture of radius and ulna } \\
\text { Ganglion of the hand excision } \\
\text { Palmar fascia contracture/release }\end{array}$ & $93.3 \%$ \\
&
\end{tabular}

AX, axillary; ICL, infraclavicular; SCL, supraclavicular.

Table 3. The proportion of the orthopedic and vascular operations

\begin{tabular}{lllll}
\hline & $\begin{array}{l}\mathrm{SCL}(n=62), \\
n(\%)\end{array}$ & $\begin{array}{l}\mathrm{ICL}(n=55), \\
n(\%)\end{array}$ & $\begin{array}{l}\mathrm{AX}(n=65), \\
n(\%)\end{array}$ & $\begin{array}{l}p \\
\text { value }\end{array}$ \\
\hline $\begin{array}{lllll}\text { Orthopedic } \\
\text { Vascular }\end{array}$ & $34(54.8)$ & $30(54.5)$ & $25(38.5)$ & 0.110 \\
& $28(45.2)$ & $25(45.5)$ & $40(61.5)$ & \\
\hline
\end{tabular}

AX, axillary; ICL, infraclavicular; SCL, supraclavicular. $p$ value assessed by Pearson's $\chi^{2}$ test.

(US) techniques have been introduced. US-guided applications provide the best-quality blocks due to the visualization of the nerves, sheath, interfascial spaces, as well as the spread of the local anesthetic compared with the conventional technique $[1,2]$.

The supraclavicular (SCL) approach to BPB is indicated for surgeries of the upper extremity distal to the shoulder; the infraclavicular (ICL) approach is indicated for surgeries of the distal arm, elbow, wrist, and hand, and the axillary (AX) route is indicated for surgeries of the elbow, forearm, and hand [3].

The need for supplementation with additional analgesics or conversion to general anesthesia indicates the quality of the nerve block. The objective of this retrospective study was to evaluate our experiences with patients on whom US-guided nerve blocks were applied.

\section{Methods}

After obtaining Institutional Review Board approval, the medical records of 182 patients aged 18-65 years with American Society of Anesthesiologists (ASA) score I-III who had undergone elective orthopedic or vascular surgery using SCL, ICL, or AX block at the level below the axilla from June 2011 to December 2012 were retrospectively evaluated. The intraoperative-postoperative anesthetic records and the follow-up clinical notes were reviewed to identify any associated complications.

Data regarding demographic characteristics, ASA physical status, underlying diseases, block type, time between the block performance and the start of the operation, duration of the operation, type of the surgeries, needle length, toxicity findings, postoperative complications, and success rates were assessed.

Exclusion criteria were patient's refusal, presence of coagulopathy, infection at the block site, any neurological deficit, severe lung disease, contralateral diaphragmatic paralysis, and allergy to local anesthetics.

On the morning before the operation, all patients were premedicated with $2 \mathrm{mg}$ intravenous midazolam. Standard screening was applied for assessing the heart rate, oxygen saturation, and noninvasive blood pressure, and $2 \mathrm{~L} / \mathrm{min}$ of oxygen was applied via a mask throughout the surgery. One of the experienced anesthesiologists performed all the blocks with $40 \mathrm{~mL}$ of $0.5 \%$ bupivacaine. In the SCL and AX groups 22-G 50-mm needles were used, while in the ICL group 22-G $80-\mathrm{mm}$ needles were used. A linear US probe was used for all patients. Additional nerve blocks were not used. A failed block was defined as the need for the addition of a strong opioid analgesic, infiltrative local anesthesia, or conversion 
Table 4. Complications

\begin{tabular}{lllll}
\hline & $\begin{array}{l}\text { SCL }(n=62), \\
n(\%)\end{array}$ & $\begin{array}{l}\text { ICL }(n=55), \\
n(\%)\end{array}$ & $\begin{array}{l}\text { AX }(n=65), \\
n(\%)\end{array}$ & $p$ value \\
\hline Horner's syndrome & $3(4.8)$ & $1(1.5)$ & $0(0)$ & $0.268^{\mathrm{a}}$ \\
Hematoma & $5(8.1)$ & $3(4.6)$ & $4(7.3)$ & $0.746^{\mathrm{a}}$ \\
Discomfort & $7(11.3)$ & $7(12.7)$ & $10(15.4)$ & $0.747^{\mathrm{b}}$ \\
\hline
\end{tabular}

AX, axillary; ICL, infraclavicular; SCL, supraclavicular. ${ }^{a}$ Fisher-Freeman-Halton exact test. ${ }^{b}$ Pearson's $\chi^{2}$ test.

to general anesthesia. The need for supplementation with additional analgesics or conversion to general anesthesia indicates the surgical anesthesia quality of the nerve block. All blocks were applied without additional neurostimulation using the $S$ nerve US machine. All blocks were performed according to the Jack Vander Beek technique in the supine position. The duration of the blocks was assessed from the skin preparation to the end of the local anesthetic administration.

Loss of sensation was assessed using the pinprick test. The motor block was assessed within $30 \mathrm{~min}$ after the injection. Discomfort during the operation because of the prolonged position was not defined as pain. Patients were evaluated $24 \mathrm{~h}$ postoperatively for the restoration of the sensory and motor function and for side effects. Pain intensity was evaluated using a visual analog scale (VAS), with a score of 0 indicating no pain and a score of 10 indicating the worst imaginable pain. Patients with VAS scores $>4$ were administered $100 \mathrm{mg}$ i.v. tramadol.

\section{Statistical Analysis}

The one-way ANOVA $t$ test was used for data showing normal distribution, and the Kruskal-Wallis test was used in cases of abnormal distribution of the variable, for comparison among continuous and ordinal variables. The Mann-Whitney U test was used for post hoc analysis in multiple comparisons. Fisher's exact test with two-tailed $p$ value calculation, computed only for $2 \times 2$ tables, was used for comparing the proportions of categorical variables among the groups.

$p<0.05$ was considered to be statistically significant.

Pearson's $\chi^{2} \mathrm{~d}$ correlation test was used for assessing the correlation between body mass index and block performance time, proportions of orthopedic and vascular operations, complications, and comorbid diseases in each group.

\section{Results}

The data of 182 patients were included in the study. Variables of 182 patients were included and analyzed statistically in this study. There were no statistically significant differences among the groups with respect to their demographic data, the time between the end of the block and the start of the operation, and the duration of the operation (Table 1). The diagnosis and the type of surgeries were similar between the groups. The success rates were 91.6\% in the AX group, 94\% in the SCL group, and 93.3\% in the ICL group (Table 2).

The proportions of orthopedic and vascular surgeries were similar with no statistically significant differences among the groups (Table 3). The classical supine position was used for all patients with $22-\mathrm{G} 50-\mathrm{mm}$ needles in the SCL and AX groups and 22-G $80-\mathrm{mm}$ needles in the ICL group. The duration of performance was $28.42 \pm 8.75 \mathrm{~min}$ in the AX group, $22.40 \pm 5.23 \mathrm{~min}$ in the SCL group, and $20.47 \pm 7.33 \mathrm{~min}$ in the ICL group. The AX block performance was significantly longer than in the other two approaches. There were no differences in hemodynamics and $\mathrm{Spo}_{2}$ measured throughout the procedure at all times. In total 7 patients in the SCL group, 10 patients in the AX group, and 7 patients in the ICL group felt discomfort due to the prolonged position or the inconvenient position on the operating table which resolved with $20-40 \mathrm{mg}$ of propofol injection. Hematoma was observed in 5 patients in the SCL group, 4 patients in the AX group, and 3 patients in the ICL group. Horner's syndrome was observed in 3 patients in the SCL group and 1 patient in the ICL group (Table 4). Horner's syndrome was transient and resolved within 24 h postoperatively in all patients. Neurological deficit was not diagnosed in any patient during the operations or postoperatively. Of the total 182 patients enrolled in our study, 14 were excluded because of the failure of the blocks. A failed block was defined as the need for the addition of strong opioid analgesics or infiltrative local anesthesia. Four patients in the SCL, 4 in the ICL, and 6 patients in the AX group felt serious pain and were converted to general anesthesia. There was no difference between the groups in the proportion of failed blocks. Five patients in the SCL group, 16 in the ICL group, and 10 patients in the AX group had diabetes mellitus. Cardiovascular diseases were found in 5 patients in the AX group, 7 patients in the ICL group, and 15 patients in the SCL group. None of them had neurological side effects. 
Table 5. Comorbid diseases

\begin{tabular}{lclll}
\hline & $\begin{array}{l}\mathrm{SCL}(n=62), \\
n(\%)\end{array}$ & $\begin{array}{l}\mathrm{ICL}(n=55), \\
n(\%)\end{array}$ & $\begin{array}{l}\mathrm{AX}(n=65), \\
n(\%)\end{array}$ & $\begin{array}{l}p \\
\text { values }\end{array}$ \\
\hline $\mathrm{DM}$ & $5(8.1)$ & $16(29.1)$ & $10(15.4)$ & $0.010^{*, a}$ \\
CVS & $15(24.2)$ & $7(12.7)$ & $5(7.7)$ & $0.028^{*, a}$ \\
COPD & $2(3.2)$ & $3(5.5)$ & $5(7.7)$ & $0.563^{\mathrm{b}}$ \\
\hline
\end{tabular}

AX, axillary; ICL, infraclavicular; SCL, supraclavicular; DM, diabetes mellitus; CVS, cardiovascular diseases; COPD, chronic obstructive pulmonary diseases. ${ }^{*} p<0.05$. ' Pearson's $\chi^{2}$ test. ${ }^{\mathrm{b}}$ Fisher-Freeman-Halton exact test.

All our patients had controlled diabetes mellitus. Two patients in the SCL, 3 patients in the ICL, and 5 patients in the AX group had chronic obstructive pulmonary disease who did not show any respiratory symptoms postoperatively (Table 5).

\section{Discussion}

US-guided nerve blocks have been increasingly popular over the past few years. The primary methods for nerve blocks before the advent of US guidance were peripheral nerve stimulator and landmark techniques. In contrast to traditional methods, US provides needle visualization for a correct identification of peripheral nerves and optimization of the distribution of the local anesthetic injection $[4,5]$. It avoids intravascular or intraneuronal injection and can be used in patients having a poor twitch response. US provides an effective and minimally invasive method of peripheral nerve block [6].

In this retrospective study, we observed that all three approaches can be applied safely for orthopedic and vascular surgeries below the shoulder. The three approaches provide adequate depth of anesthesia and quality of surgery.

Stav et al. [7] compared the US-guided technique of SCL-ICL and AX block technique in 101 patients. Similar to our findings below the shoulder, they stated that all three approaches can be safely used for BPB. With USguided $\mathrm{BPB}$, no serious complications were encountered.

In another study, Chan et al. [4] demonstrated that US guidance improved the success rate of BPB. With similar results, Qin et al. [8] evaluated real-time US guidance for BPB in 2,042 patients. In their multicenter study, they demonstrated that US guidance improved the success rate and reduced the mean time of onset of anesthesia.
In another study, Hadzic et al. [9] compared general anesthesia with BPB for upper extremity surgeries. They concluded that the ICL approach provided time-efficient and better analgesia and greater patient acceptance with faster recovery.

The most common fractures of the upper extremity in young people are caused due to traumas. Lung contusions are frequently observed in trauma patients with upper extremity problems. General anesthesia can increase the morbidity. In our clinic, we prefer nerve blocks in trauma patients, especially for respiratory problems or underlying comorbid diseases. In case of emergency, all three approaches can be safely applied. In our study, we did not need the addition of any additional blocks or subcutaneous infiltrations. In the SCL and ICL groups, block performance times were similar but longer in the AX group with no clinical importance.

Franco and Vieira [10] collected 1,001 consecutive BPB blocks and observed them using a single shot technique and found no major clinical complications. In our study we also did not observe any major complication due to the technique performed by the experienced anesthesiologist.

In another study, Hörmet and Ayşenur [11] compared US-guided BPB with the classic nerve stimulator $\mathrm{BPB}$ technique. They concluded that the US-guided neurostimulator technique had better results than the classic neurostimulator technique.

Patients with chronic obstructive pulmonary disease, morbid obesity, older age and diabetes must be carefully evaluated preoperatively. Phrenic nerve block can reduce forced vital capacity. Respiratory complications can increase postoperatively, hence it is necessary to select patients carefully.

Our study had some limitations. It was a retrospective study with a small sample size conducted in a single center. In addition, there may be more side effects than we actually found because the patients' follow-up examinations were stopped or lost as it was a retrospective study.

\section{Conclusions}

Peripheral nerve blocks are cost-effective techniques that provide an adequate quality of anesthesia and analgesia while preventing problems associated with general anesthesia.

US-guided BPB can be applied using the three approaches and provide the same quality of surgical anesthesia for upper extremity operations with no serious complications.
Tarıkçı Kılıç/Akdemir 


\section{Statement of Ethics}

The authors confirm that all the subjects gave their written informed consent and that the study protocol was approved by the research institute's Ethics Committee. The study was conducted in accordance with the World Medical Association Declaration of Helsinki.

\section{Disclosure Statement}

The authors have no conflicts of interest to declare.

\section{References}

1 Orebaugh SL, Bigeleisen PE. UltrasoundGuided Supraclavicular Block. In: Bigeleisen PE, editor. Ultrasound-Guided Regional Anesthesia and Pain Medicine. Philadelphia (PA): Lippincott Williams \& Wilkins; 2010. pp. 53-7.

2 Orebaugh SL, Groen GJ, Bigeleisen PE. Ultrasound-Guided Infraclavicular Block. In: Bigeleisen PE, editor. Ultrasound-Guided Regional Anesthesia and Pain Medicine. Philadelphia (PA): Lippincott Williams \& Wilkins; 2010. pp. 58-64.

3 Orebaugh SL, Groen GJ, Bigeleisen PE. Ultrasound-Guided Axillary Block. In: Bigeleisen PE, editor. Ultrasound-Guided Regional Anesthesia and Pain Medicine. Philadelphia (PA): Lippincott Williams \& Wilkins; 2010. pp. 65-70.
4 Chan VW, Perlas A, McCartney CJ, Brull R, $\mathrm{Xu} \mathrm{D}$, Abbas S. Ultrasound guidance improves success rate of axillary brachial plexus block. Can J Anaesth. 2007 Mar;54(3):17682.

5 Sites BD, Beach ML, Spence BC, Wiley CW, Shiffrin J, Hartman GS, et al. Ultrasound guidance improves the success rate of a perivascular axillary plexus block. Acta Anaesthesiol Scand. 2006 Jul;50(6):678-84.

6 Vander Beek J. Axillary Brachial Plexus Block. In: Vander Beek J, editor. The Neuraxiom Playbook of 9 Essential Blocks: A Handbook of Ultrasound Guided Regional Nerve Blocks. 1st ed. USA: Neuraxiom LLC; 2009. pp. 8691.

7 Stav A, Reytman L, Stav MY, Portnoy I, Kantarovsky A, Galili O, et al. Comparison of the Supraclavicular, Infraclavicular and Axillary Approaches for Ultrasound-Guided Brachial Plexus Block for Surgical Anesthesia. Rambam Maimonides Med J.2016 Apr;7(2):e0013.
8 Qin Q, Yang D, Xie H, Zhang L, Wang C. Ultrasound guidance improves the success rate of axillary plexus block: a meta-analysis. Braz J Anesthesiol. 2016 Mar-Apr;66(2):115-9.

9 Hadzic A, Arliss J, Kerimoğlu B. A comparison of infraclavicular nerve block versus general anesthesia for hand and wrist day case surgeries. Anesthesiology 2004; 101(1):12732.

10 Franco CD, Vieira ZE. 1,001 subclavian perivascular brachial plexus blocks: success with a nerve stimulator. Reg Anesth Pain Med. 2000 Jan-Feb;25(1):41-6.

11 Hörmet A, Ayșenur Ö. Aksiller Brakiyal Pleksus Bloğunda Nörostimülatör Tekniği ile Ultrasonografi Esliğinde Nörostimülatör Tekniğinin Karşılaştırılması. GKDA Derg. 2017;23(2):48-54 